\title{
Multiple Streamtube Approximation of Flow Induced Forces on a Savonius Wind Turbine
}

\author{
Kevin Pope ${ }^{1}$ and Greg F. Naterer ${ }^{2}$ \\ University of Ontario Institute of Technology, Oshawa, Ontario, Canada
}

\begin{abstract}
This paper develops a new approximate model to predict the pressure and momentum forces on a Savonius style VAWT (vertical axis wind turbine). Flow distributions through and around the turbine are examined for analytical predictions of the torque and power output, at all rotor angles. A new approximate streamtube method is developed to predict the momentum, lift and drag forces on the rotor surfaces by the air stream, based on an integral force balance on the turbine blades. Unlike other past analytical methods, the technique predicts both momentum and pressure forces imposed on the rotor surface during operation. The calculated results are carefully compared with numerical predictions from CFD (computational fluid dynamics).
\end{abstract}

\section{Nomenclature}

a radius of semi-cylindrical blade [m]

A area per unit turbine height $\left[\mathrm{m}^{2} / \mathrm{m}\right]$

$C_{\mathrm{p}} \quad$ power coefficient

$d \quad$ distance to origin [m]

$g \quad$ acceleration of gravity $\left[\mathrm{m} / \mathrm{s}^{2}\right]$

$p \quad$ pressure $[\mathrm{Pa}]$

\footnotetext{
${ }^{1} \mathrm{PhD}$ candidate. Faculty of Engineering and Applied Science University of Ontario Institute of Technology, 2000 Simcoe St, Oshawa, Ontario, Canada, L1H 7K4, kevin.pope@mycampus.uoit.ca

${ }^{2}$ Associate Dean and Canada Research Chair Professor. Faculty of Engineering and Applied Science, University of Ontario Institute of Technology, 2000 Simcoe Street North, Oshawa, Ontario, Canada, L1H 7K4, greg.naterer@uoit.ca
} 


$\begin{array}{ll}\mathrm{Q} & \text { torque }[\mathrm{N}-\mathrm{m}] \\ R & \text { turbine radius }[\mathrm{m}] \\ S & \text { solidity } \\ t & \text { time }[\mathrm{s}] \\ u & \text { x-component of velocity }[\mathrm{m} / \mathrm{s}] \\ U & \text { free-stream velocity }[\mathrm{m} / \mathrm{s}] \\ V & \text { y-component of velocity }[\mathrm{m} / \mathrm{s}] \\ V & \text { mean wind velocity }[\mathrm{m} / \mathrm{s}] \\ W_{\mathrm{x}} & \text { x-component of relative wind velocity }[\mathrm{m} / \mathrm{s}]\end{array}$

\section{Greek}

$\begin{array}{ll}\beta & \text { rotor overlap [m] } \\ \theta & \text { rotor position [radians] } \\ \lambda & \text { tip speed ratio } \\ \mu & \text { dynamic viscosity of air [Pa-s] } \\ \rho & \left.\text { air density [kg } / \mathrm{m}^{3}\right] \\ \phi & \text { semi-cylindrical coordinate } \\ \Psi & \text { stream function } \\ \Omega & \text { rotor velocity [radians/s] }\end{array}$

\section{Subscripts}

$\begin{array}{ll}\mathrm{m} & \text { momentum } \\ \mathrm{p} & \text { pressure } \\ \mathrm{x} & \text { drag } \\ \mathrm{y} & \text { lift }\end{array}$




\section{$\underline{\text { 1. Introduction }}$}

Wind power is becoming an increasingly significant source of sustainable power generation, for example growing at $23.6 \%$ in 2010 [1], and providing a valuable synergy with other carbon-free technologies (such as solar, nuclear and geothermal) [2]. Wind power can supplement current power generation methods while mitigating environmental degradation and resource depletion [3]. Although horizontal axis wind turbines (HAWTs) represent the majority of the installed wind capacity, many opportunities exist for small vertical axis wind turbine (VAWT) installations to achieve significant future growth. A wide variety of small wind turbine applications can be fulfilled by VAWTs. Advantages of a VAWT over a HAWT include a simpler design and omni-directional operation (omitting the need for a yaw mechanism). These attributes reduce maintenance and installation expenses, due to the reduced complexity of the system, compared to a HAWT.

Several types of VAWT designs are known, each with unique benefits and drawbacks. The most common are the Darrieus, H-rotor, and Savonius VAWTs. The Savonius turbine has the lowest maximum efficiency of these three VAWTs; however, it has several useful attributes that motivate further development. Compared to the other VAWTs, this design can more effectively operate in turbulent conditions. For example, it has been shown in several studies that its performance is independent of the Reynolds number of the air stream [4, 5]. The L-sigma criterion [6], which considers the frontal area of a turbine and the mechanical stresses during operation, identified the Savonius VAWT as advantageous over other types of turbines (including HAWTs). It was also reported to have better start-up capabilities and lower tip-speed-ratios $(\lambda)$.

There is significant potential to combine a Savonius design with a Darrius or H-rotor design to effectively utilize the benefits of each geometry in a hybrid type VAWT $[7,8]$. Reducing the 
environmental impact of residential, commercial, and industrial buildings can substantially reduce overall carbon emissions, and small wind turbines are a promising technology for renewable power production in a populated environment [9]. A HAWT typically provides poor potential in this environment [10], but a small hybrid VAWT can provide significant power generation. Recent advances in generator technology have identified radial coreless synchronous generators as a potential candidate for small VAWT installations, where its small size and low start-up speed coincide with the requirements of a Savonius VAWT [11].

The performance of any wind turbine is highly sensitive to the wind conditions at the installation location. Wind conditions can be highly non-uniform and the turbine must operate through a wide range of tip-speed-ratios [12], no single blade geometry gives optimal performance for all values of $\lambda$ [13], and the power output of a Savonius VAWT is highly sensitive to the blade geometry [14]. In contrast to other methods, where a single maximum power coefficient is defined, at one particular wind speed $[15,16]$, to achieve optimal performance, the blade geometry should be designed to effectively match the operating conditions of the installation site. Considering the effects of various wind velocity distributions and their effects on $\lambda$ and the system's start-up capabilities, these factors can significantly improve the total power output. Even sites without sufficient wind speed data can utilize spatial estimation techniques to accurately predict the conditions at the installation site [17]. The turbine operation involves complicated flow patterns that vary with time throughout the rotation of the rotor. Transient numerical simulations can provide a useful tool to provide insight about the operation of a Savonius turbine, for a wide range of $\lambda$, as an alternative to wind tunnels, or field testing of prototype turbines. Transient aerodynamic loading is a key issue that influences the overall cost of wind power generation, because it affects the operation, availability, power quality, and energy yield of each installation [18]. 
Previous research has determined that the predictive accuracy of wind turbine installations are more closely linked to the accuracy of the aerodynamic model than the electromechanical model [19]. VAWT models can be categorized into three main divisions: (i) momentum (streamtube), (ii) discrete vortex, and (iii) cascade models [20]. However, these current predictive VAWT models cannot be effectively applied to drag type turbines (such as a Savonius VAWT). Steamtube techniques use static airfoil lift and drag coefficients, with local angles of attack and relative velocities [21]. The operation of a Darrieus VAWT can be represented well by this technique, as corresponding airfoil data is available and there is no significant interaction between the rotor blades. A single streamtube was successfully applied to a single blade Savonius VAWT [22]. However, it cannot represent the operation when a second blade is added. The discrete vortex method has been applied to a Savonius rotor [23 - 25], but a complex iterative solution was required to obtain a solution. This method could not accurately represent a stationary rotor (important for start-up), and it required calculations to be performed at much higher Reynolds numbers than flow conditions of available experimental data [24]. The third approach (cascade model) represents the rotation of rotors as a linear series of blades [26]. This technique cannot represent the flow interaction between blades or the changing blade profile throughout the rotation. As a result, it does not accurately represent the operation of a Savonius turbine.

In this paper, a new predictive model is developed to analyze the momentum, lift and drag forces created from the flow fields generated during the operation of a Savonius VAWT. In contrast to previous techniques, where only the momentum force is represented, this model considers momentum, lift and drag forces to develop a transient model to predict the operation of a Savonius wind turbine. The vector flow field is represented by the superposition of approximate flow fields from potential flow theory, to analyze the pressure force, induced by the velocity 
differential of the passing air stream. The momentum force is predicted from the linear momentum equation, and the results combined with pressure force calculations. This formulation provides a new analytical tool to predict the operating performance and improve the characteristics of drag type VAWTs.

\section{Formulation of Flow Field and Velocity Distribution}

Complicated flow fields and velocity distributions are developed during the operation of a Savonius wind turbine. As illustrated in Fig. 1, a typical Savonius turbine consists of two curved blades, separated by $180^{\circ}$, with a gap and overlap in between the rotor centers. A wide variety of blade curvatures and spacings can be utilized, with every design producing distinct operational attributes. These flow fields impart multiple forces on the turbine which vary at all rotor positions. In this section, the forces on a rotating blade of a Savonius wind turbine are predicted by combining a multiple streamtube formulation (linear momentum theory) with pressure forces induced by the velocity distribution at the rotor surface. In contrast to typical techniques, both momentum $\left(F_{x, m}\right)$ and pressure $\left(F_{y, p}\right.$ and $\left.F_{x, p}\right)$ forces are represented by this method. The torque $(Q)$ on the blade can be predicted by the following equation, which includes the momentum, lift and drag forces.

$$
Q=d \cdot\left(F_{y, p} \cos \theta-F_{x, p} \sin \theta+F_{x, m}\right)
$$

where $d$ and $\theta$ represent the distance from the acting point of the force to the axis of rotation and rotor position, respectively. As illustrated in Fig. 2, the origin of $\theta$ is located when the rotor is pointing towards the back of the turbine, with respect to the oncoming wind, in counter-clockwise rotation.

The ratio of the blade area to the rotor swept area of a turbine represents the degree to which the turbine behaves as a solid in the oncoming air stream. This is characterized by the 
turbine's solidity, $S=\frac{A}{R}$. This solidity of a turbine corresponds to the blockage effect acting on the air stream. A Savonius turbine has a high solidity, as it represents operating conditions where the blockage is prominent. The air stream experiences a significant blockage effect as it flows into the turbine area. The mean average wind speed is slightly lowered in the region of the turbine, including the windward side. As the air stream flows into the turbine rotors, there is a localized transfer of momentum from the air to the rotor blade. A momentum balance can represent these processes.

As illustrated in Fig. 1, the momentum imparts a significant portion of the operating forces, during both the power and return strokes. As the rotor rotates into the wind (return stroke), the air is deflected off the convex curved rotor surface, transferring momentum, and reducing performance. A control volume approach will be adopted to represent the forces imposed on the rotor blades by the deflected air, with the boundary of the control volume encompassing the rotor blades. The difference between the momentum of the air stream entering and exiting the control volume yields the forces which oppose the rotor rotation during the return stroke. As the rotor rotates with the flow of wind (power stroke), the air impinging on the concave side of the blade is represented by its transfer of momentum. The flow, deflected by the curved blade, exits the control volume at the tip of the blade. For a semi-cylindrical blade, this is opposite to the instantaneous rotation vector. Thus, the sum of the flow entering and exiting the control volume contributes to the rotational forces.

The net rate of change of momentum across the control surface (encompassing the turbine blade) is affected by the change in linear velocity as the air flows into and out of the control volume. To represent a Savonius turbine, two independent streamtubes will be considered: one for the power stroke, and another for the return stroke, respectively. The exit velocity differs for the 
power and return strokes, which requires a piecewise function. Thus, to represent the momentum force for a rotating Savonius blade, this can be represented by

$$
F_{x, m}(\theta)= \begin{cases}-\left(W_{x} \rho A W_{x}+W_{x} \rho A\left(-W_{x} \cdot \sin \frac{\pi}{2}\right)\right), & \text { if } 0 \leq \theta<\pi \\ W_{x} \rho A W_{x}+W_{x} \rho A W_{x}, & \text { if } \pi \leq \theta<2 \pi\end{cases}
$$

where $W_{\mathrm{x}}$ represents the $\mathrm{x}$-component of relative wind velocity (i.e. parallel to the free stream wind direction). The area per unit turbine height, $A$, is a function of the angular position, $\theta$, to account for the changing cross section of the turbine blade, relative to the free-stream, as it rotates about the central axis,

$$
A(\theta)=a \cdot(1+|\sin \theta|)
$$

where $a$ represents the radius of the turbine's rotor blade. The relative velocity of the air leaving the blade on the return stroke is expressed by $-W_{x} \cdot \sin \frac{\pi}{2}$ to account for the angle at which the air is deflected by the convex curve $\left(-\sin \frac{\pi}{2}\right)$. During the power stroke, the air is deflected by $180^{\circ}$, allowing $W_{\mathrm{x}}$ to represent the relative exit velocity during the power stroke. The turbine rotation causes the control volume to rotate around a central axis, which changes the relative wind velocity at the rotor blades, at different values of $\theta$. The wind velocity (parallel to the free-stream) relative to the rotor blade can be expressed as

$$
W_{x}(\theta)=U+d \Omega \sin \theta
$$

As illustrated in Figs. 2 and 3, the variables $U, \theta$, and $d$ represent the free-stream velocity, angular position of the blade surface (relative to the free-stream), and the distance to the acting point of the forces. The variable $\Omega$ represents the rotor velocity.

The forces are estimated to act at the position which centers between the front edge of the blade and the location of separation (the magnitude of $d$ represents the linear distance from the center of rotation to the estimated acting point of the forces). The location of flow separation from 
the blade is assumed to occur at a location of $\phi \approx 108.8^{\circ} \approx 1.90$ radians [27], where $\phi$ represents the angular position along the rotor surface (Fig. 4), with its origin at the front edge of the turbine blade (i.e. the outboard edge at $90^{\circ}$ to $270^{\circ}$ inboard edge during $270^{\circ}$ to $90^{\circ}$ ). With a rotor position at $\theta=0^{\circ}$, one half of the linear distance (parallel to the free-stream) from the origin to the location of flow separation is

$$
\mathrm{d}(0)=\frac{1}{2}\left[(a-\beta)+a \sin 18.8^{\circ}\right]
$$

where $\beta$ and $a$ represent the rotor overlap and blade radius, respectively. The first two variables (i.e. $\left.\frac{1}{2}(a-\beta)\right)$ represent the distance to the center of the rotor, $\phi=90^{\circ}$, or one half of the rotor. The last term (i.e. $a \sin 18.8^{\circ}$ ) estimates the remaining distance to the location of flow separation. As illustrated in Fig. 5, at $\theta=180^{\circ}$, the magnitude of $d$ can be represented by

$$
d\left(180^{\circ}\right)=\left[(a-\beta)+a \sin 35.6^{\circ}\right]
$$

which is equivalent to

$$
\begin{gathered}
d\left(180^{\circ}\right)=\frac{1}{2}\left[(a-\beta)+a \sin 18.8^{\circ}\right]+\left[(a-\beta)+a \sin 35.6^{\circ}\right]-\frac{1}{2}[(a \\
\left.-\beta)+a \sin 18.8^{\circ}\right]
\end{gathered}
$$

The cyclic trends in the magnitude of $d$, caused by the rotor rotation, are represented with the following functional form,

$$
\begin{gathered}
d(\theta)=\frac{1}{2}\left[(a-\beta)+a \sin 18.8^{\circ}\right]+\left\{\left[(a-\beta)+a \sin 35.6^{\circ}\right]-\frac{1}{2}[(a-\right. \\
\left.\left.\beta)+a \sin 18.8^{\circ}\right]\right\} \sin \left(\frac{\theta}{2}\right)
\end{gathered}
$$

Equation (8) is rearranged to obtain the following simplified form, 


$$
\begin{gathered}
d(\theta)=\frac{1}{2}\left[(a-\beta)+a \sin 18.8^{\circ}\right][1-\sin (\theta / 2)]+[(a-\beta) \\
\left.+a \sin 35.6^{\circ}\right] \sin (\theta / 2)
\end{gathered}
$$

With this formulation a stream function is used, only in regions of the curved blade's exterior, located before the separation point. Although a stream function does not precisely represent the flow over a Savonius blade, this assumption provides a useful basis for determining the location of flow separation from the rotor, and the subsequent effect of pressure forces on the turbine.

To predict the pressure forces $\left(F_{y, p}\right.$ and $\left.F_{x, p}\right)$, consider an unsteady flow field represented by a series of steady streamlines that change with angular position. By combining potential and doublet flow, the pressure distribution along the convex side of a semi-cylindrical blade surface, with no blade separation, can be predicted by [27],

$$
p_{s}=p_{0}+\frac{1}{2} \rho U^{2}\left(1-4 \sin ^{2} \phi\right)
$$

where $\mathrm{p}_{\mathrm{o}}$ and $\mathrm{p}_{\mathrm{s}}$ represent the ambient and surface pressures, respectively.

Combining the surface pressure, Eq. (10), with the relative wind speed, Eq. (4), the operational force induced by the pressure differential on a semi-cylindrical Savonius blade can be predicted. The 2-D components of the pressure forces along the blade can be represented by

$$
\begin{aligned}
& F_{p, x}=-\int_{\xi_{1}(\theta)}^{\xi_{2}(\theta)}\left[p_{0}+\frac{1}{2} \rho W_{x}^{2}\left(1-4 \sin ^{2} \phi\right) \cos \phi a\right] d \phi \\
& F_{p, y}=-\int_{\xi_{1}(\theta)}^{\xi_{2}(\theta)}\left[p_{0}+\frac{1}{2} \rho W_{x}^{2}\left(1-4 \sin ^{2} \phi\right) \sin \phi a\right] d \phi
\end{aligned}
$$

where the integral limits are defined as $\xi_{1}(\theta)=0-\theta$ and $\xi_{2}(\theta)=\pi-\theta$, which correspond to the transient positioning of a rotor blade as it rotates around the central axis.

Equations (11) and (12) predict the pressure forces induced by the variations in the flow field, along the rotor blades. The effects of flow separation experienced by the turbine operation 
are included in these equations. As illustrated in Figs. 1, 4 and 5, the flow around the semicylindrical blade has an effect on performance for both the power and return stokes. During the power stroke, the flow around the outside of the curved blade is represented, which includes a lift and drag component. However, during a significant portion of the stroke, the flow separation will limit these forces, because of boundary layer detachment.

With a correction factor, $C$, to represent the interaction between multiple rotor blades, equations (2), (11) and (12) are combined to predict the torque on the rotor blades, Eq. (1), allowing the torque coefficient (per unit height) to be determined by

$$
C_{Q}=C \frac{Q}{4 \rho R^{2} U^{2}}
$$

where $2 a-\beta$ represents the turbine radius, $R$. Similarly, the power coefficient (per unit height) can be determined by

$$
C_{P}=C \frac{Q \Omega}{2 \rho R U^{3}}
$$

With the above formulation, these coefficients can be used to predict the general trends and overall effects of blade interaction on torque and power output.

\section{$\underline{\text { 5. Results and Discussion }}$}

In this section, the transient power output of a Savonius wind turbine is explored by comparing the new analytical model with previous experiments and CFD predictions. Transient power coefficients are first developed for a single blade Savonius turbine, negating any blade interaction, and allowing investigation of a Savonius VAWT's operation by identifying both accuracies and inaccuracies in the new predictive model. Secondly, transient torque coefficients (with the new predictive model and CFD simulations) are developed and compared with previous 
experimental data, to help identify the effect of blade interaction on power output. The simplifications and assumptions adopted in developing the model can help to better understand the complex flow phenomena rotating a Savonius VAWT.

As illustrated in Fig. 2, the simulated turbine has semi-cylindrical rotor blades with a rotor radius, $a$, of $0.50 \mathrm{~m}$ and an overlap, $\boldsymbol{\beta}$, of $0.10 \mathrm{~m}$. A wind velocity of $10 \mathrm{~m} / \mathrm{s}$ is assumed for consistency between the analytical and numerical predictions, with the turbine operating at a tipspeed-ratio, $\lambda$, of 0.5 . As the wind flows around the rotating rotor blades, a pressure differential is developed along the blade surface. The numerical CFD data [28] are formulated with 2-D rotating blade (transient) simulations, which predict an average power coefficient of 0.062 and 0.176 for the single and double blade VAWT, respectively. These results closely match past experimental results throughout the entire range of angular position, including accurate predictions through the transitions angles between the power and return strokes of the rotors rotation (see Refs. [29] and [30] for experimental results).

Figure 6 illustrates the single blade numerical predictions, normalized by dividing by a reference $C_{\mathrm{p}}$ of 0.19 (the highest instantaneous output predicted by the CFD simulations). From $180^{\circ}$ to $360^{\circ}$, during the power stroke, close agreement is achieved between the normalized CFD and analytical predictions. However, there are some discrepancies from $0^{\circ}$ to $90^{\circ}$, between the analytical and CFD predictions. In particular, the estimated torque is higher than the CFD predictions for the first $90^{\circ}$ of rotation, likely due to over-estimated lift forces at these angular positions, since Eq. (12) predicts equivalent pressure lift forces $\mathrm{F}_{\mathrm{y}, \mathrm{p}}$ at $0^{\circ}$ and $180^{\circ}$.

As illustrated in Figs. 6 and 7, the effect of varying the rotor blade number has a significant impact on the power output because of the blade interaction. A second rotor blade can alter the mass flow rate into the control volume of the blades, as well as alter the pressure distributions on 
the concave side of the rotor blades, particularly during the return stroke. Adding a second rotor blade increases the power output by a factor of 2.8. This positive effect on power output can be attributed to deflected air from the power stroke entering the concave side of the return stroke, through the overlap opening, thereby lowering the negative pressure on the backside of the return rotor blade. Secondly, some of the air will deflect off the convex side of the return stroke and increase the momentum of the air impacting the front surface of the power stroke [31]. Both of these geometrically induced flow fields have a positive effect on performance and they increase the power output from the turbine. The result for the analytical formulation is that two blades cannot be calculated with two independent single blade calculations, considered independently with a $180^{\circ}$ offset, i.e. $C_{p, 2}(\theta) \neq C_{P, 1}(\theta)+C_{P, 1}\left(\theta+180^{\circ}\right)$. As further illustrated by Fig. 7, which compares this negated relation of two single-blade turbines combined with a $180^{\circ}$ offset of rotor position, with the two-blade numerical predictions, significant variability is evident between the two curves.

In Fig. 8, $\Delta \mathrm{C}_{\mathrm{Q}}$ is obtained based on the difference in the numerical predictions for a one or two rotor blade turbine (with all other parameters unchanged), thus predicting the trends associated with changes in operational forces generated by blade interaction. This information can be used to predict $C$ as a function of $\theta$. A sinusoidal trend line closely follows the trends as follows,

$$
C=0.065+0.15 \sin \left(\frac{\theta}{2}\right)
$$

The sinusoidal shape with two peaks during one rotation can be explained by the cyclical trends in the two forces discussed previously. Equation (15) provides important insights into the overall effects of the flow interaction between rotors in a two-blade design. The effects of adding a second blade to a Savonius wind turbine causes a complex interaction of vortices, and changes to the flow 
separation regime within the turbine. As illustrated in Fig. 8, these effects can be accurately predicted, to a relatively high degree of accuracy, with a simple sinusoidal function.

As illustrated in Fig. 9, the new formulation can estimate the power coefficient of a twoblade Savonius VAWT with relative accuracy. This figure compares calculated output, for a twoblade Savonius VAWT, with numerical predictions. By comparing the transient torque coefficient for one and two-blade turbines, the flow interaction can be investigated. The positive effect on performance, caused by the blade interaction in a two blade design, is an important attribute of a Savonius wind turbine. The addition of a second rotor blade and its subsequent affect on the transient power coefficient is an important consideration for accurate predictions of power output for a Savonius wind turbine.

In Fig. 10, the sensitivity of $C$ on the predictive results is presented. The value of $C$ is reduced to two separate values: $C=0.03+0.15 \sin \left(\frac{\theta}{2}\right)$ and $C=0.15 \sin \left(\frac{\theta}{2}\right)$. Reducing the magnitude of $C$ can more closely match the results of the predictive model to experimental data, by compensating for some inconsistencies between the assumptions of the model and the complex fluid flow which operates a Savonius wind turbine.

This analysis highlights the transient difference in torque and power output for a single and double blade configuration. Although it does not represent the detailed and complex behaviour of vortices that are generated, and partly captured by the second blade in the two-blade design, it provides a useful new design tool for overall trends and key features. It improves over past analytical models in terms of physical mechanisms that affect the turbine's transient behaviour. Design modifications based on the new analytical model can be made to improve system performance. For example, with a hybrid design, the flow interactions between the inner Savonius 
design can be analyzed with the model, in conjugation with outer lift type turbines (typically Darrieus or H-rotor designs) to improve the performance and power output.

Advancements in the understanding of the complex interactions between two blades can help to improve turbines which utilize a Savonius style rotor blade. The simplicity and accuracy of Eq. (15), with a variable used to represent a set of physical flow interactions and changes in the turbine's flow field, offers valuable utility to the development and improvement of VAWT designs. Although this predictive model can approximate the transient output of a Savonius VAWT, further research associated with different operating conditions is required to determine the model's range of validity. These results are beneficial to understanding the torque and power output effects, for a two-blade Savonius wind turbine, among other similar configurations.

\section{Conclusions}

In this paper, a new approximate formulation was developed to predict the power output and dynamic forces on a Savonius VAWT. The velocity field associated with the flow over a semicylindrical rotor was combined with a momentum theory solution to provide a new method to represent the transient power coefficient of a VAWT. A sinusoidal function was developed to predict the interaction associated with the addition of a second rotor blade. These results provide a useful tool to analyze the operation of a Savonius VAWT. Using this new predictive formulation, significant opportunity exists to improve the performance of a Savonius style VAWT.

\section{Acknowledgements}

Financial support from the Natural Sciences and Engineering Research Council of Canada and Zephyr Alternative Power Inc. is gratefully acknowledged. 


\section{References}

[1] WWEA. World Wind Energy Report 2010. Wind Energy Association, Charles-de-GaulleStr. 5, 53113 Bonn, Germany, 2011.

[2] Miller AI, Duffey RB. Sustainable supply of global energy needs and greenhouse gas reductions. Transactions of the Canadian Society for Mechanical Engineering 2009; 33(1): 1-10. [3] Hammond GP. Engineering sustainability: thermodynamics, energy systems, and the environment. International Journal of Energy Research; 2004; 28: 613-639.

[4] Ghosh P, Kamoji MA, Kedare SB, Prabhu SV. Model testing of single- and three-stage modified Savonius rotors and viability study of modified Savonius pump rotor systems. International Journal of Green Energy 2009; 6(1): 22-41.

[5] Kamoji MA, Kedare SB, Prabhu SV. Experimental investigations on the effect of overlap ratio and blade edge conditions on the performance of conventional Savonius rotor. Wind Engineering 2008; 32(2): 163-178.

[6] Menet JL, Valdes LC, Menart B. A comparative calculation of the wind turbines capacities on the basis of the $L-\sigma$ criterion. Renewable Energy 2001; 22: 491-506.

[7] Gavalda J, Massons J, Diaz F. Experimental study on a self-adapting Darrieus-Savonius wind machine. Solar \& Wind Technology, 1990; 7(4): 427-461.

[8] Wakui T, Tanzawa Y, Hashizume T, Nagao T. Hybrid configuration of Darrieus and Savonius rotors for stand-alone wind turbine-generator systems. Electrical Engineering in Japan 2005; 150(4): 13-22. 
[9] Gordon C, Fung A. Hourly emission factors from the electricity generation sector $-\mathrm{a}$ tool for analyzing the impact of renewable technologies in Ontario. Transactions of the Canadian Society for Mechanical Engineering 2009; 33(1): 105-118.

[10] Heath MA, Walshe JD, Watson SJ. Estimating the potential yield of small buildingmounted wind turbines. Wind Energy 2007; 10: 271-287.

[11] Takahashi T, Yasuda Y, Ohmoto S, Hara T. Proposal and development of radial air-gap coreless generator suitable for small wind turbine used in urban area. Electrical Engineering in Japan 2009; 167(1): 26-34.

[12] Alawi H. Designing reliably for wind energy. Transactions of the Canadian Society for Mechanical Engineering 1998; 12(3): 173-179.

[13] Mojola OO. On Aerodynamic design of the Savonius windmill rotor. Journal of Wind Engineering and Industrial Aerodynamics 1985; 21: 223-231.

[14] Sivasegaram S. Wind Tunnel Tests on Slow-Running Vertical-Axis Wind-Rotors. Proceedings of the Indian Academy of Science 1981; 4(3): 395-404.

[15] Johansen J, Madsen HA, Gaunna M, Bak C. Design of a wind turbine rotor for maximum aerodynamic efficiency. Wind Energy 2009; 12: 261-27.

[16] Anahua E, Barth S, Peinke J. Markovian power curves for wind turbines. Wind Energy 2008; 11: 219-232.

[17] Mohandes MA, Rehman S, Rahman SM. Spatial estimation of wind speed. International Journal of Energy Research; 2010.

[18] Schreck SJ, Sørensen NN, Robinson MC. Aerodynamic structures and processes in rotationally augmented flow fields. Wind Energy 2007; 10(2): 159-178. 
[19] Elizondo J, Martınez J, Probst O. Experimental study of a small wind turbine for low- and medium-wind regimes. International Journal of Energy Research; 2009; 33: 309-326.

[20] Islam M, Ting DS, Fartaj A. Aerodynamic models for Darrieus-type straight-bladed vertical axis wind turbines. Renewable and Sustainable Energy Reviews 2008; 12: 1087-1109.

[21] Spera DA. Wind Turbine Technology Fundamental Concepts of Wind Turbine Engineering. ASME Press: New York, 1994.

[22] Kyozuka Y. An experimental study on the Darrieus-Savonius turbine for the tidal current power generation. Journal of Fluid Science and Technology 2008; 3(3): 439-449.

[23] Fernando MS, Modi VJ. A numerical analysis of the unsteady flow past a Savonius wind turbine. Journal of Wind Engineering and Industrial Aerodynamics, 1989; 32: 303-327.

[24] Fujisawa N. Velocity measurements and numerical calculations of flow in and around Savonius rotors. Journal of Wind Engineering and Industrial Aerodynamics. 1996; 59: 39-50.

[25] Kotb MA, Aldoss TK. Flowfield around a partially-blocked Savonius rotor. Applied Energy 1991; 38: 117-132.

[26] El-Wakil MM. Powerplant Technology. McGraw-Hill: New York, 1984.

[27] Munson BR, Young DF, Okiishi TE. Fundamentals of Fluid Mechanics $5^{\text {th }}$ ed. Jefferson City, USA: John Wiley and Sons, 2006.

[28] Pope K, Naterer GF, Tsang E. Effects of rotor-stator geometry on vertical axis wind turbine performance. Canadian Society for Mechanical Engineers 2008 forum, June 5-8, Ottawa, Canada, 2008.

[29] Blackwell BF, Sheldahl RE, Feltz LV. Wind Tunnel Performance Data for Two- and Three-Bucket Savonius Rotors. Sandia Laboratories 1977: SAND76-0131. 
[30] Gavalda J, Massons J, Diaz F. Experimental study on a self-adapting Darrieus-Savonius wind machine. Solar and Wind Technology 1990; 7(4): 457-461.

[31] Murai Y, Nakada T, Suzuki T, Yamamoto F. Particle tracking velocimetry applied to estimate the pressure field around a Savonius turbine. Measurement Science and Technology 2007;

18: 2491-2503. 


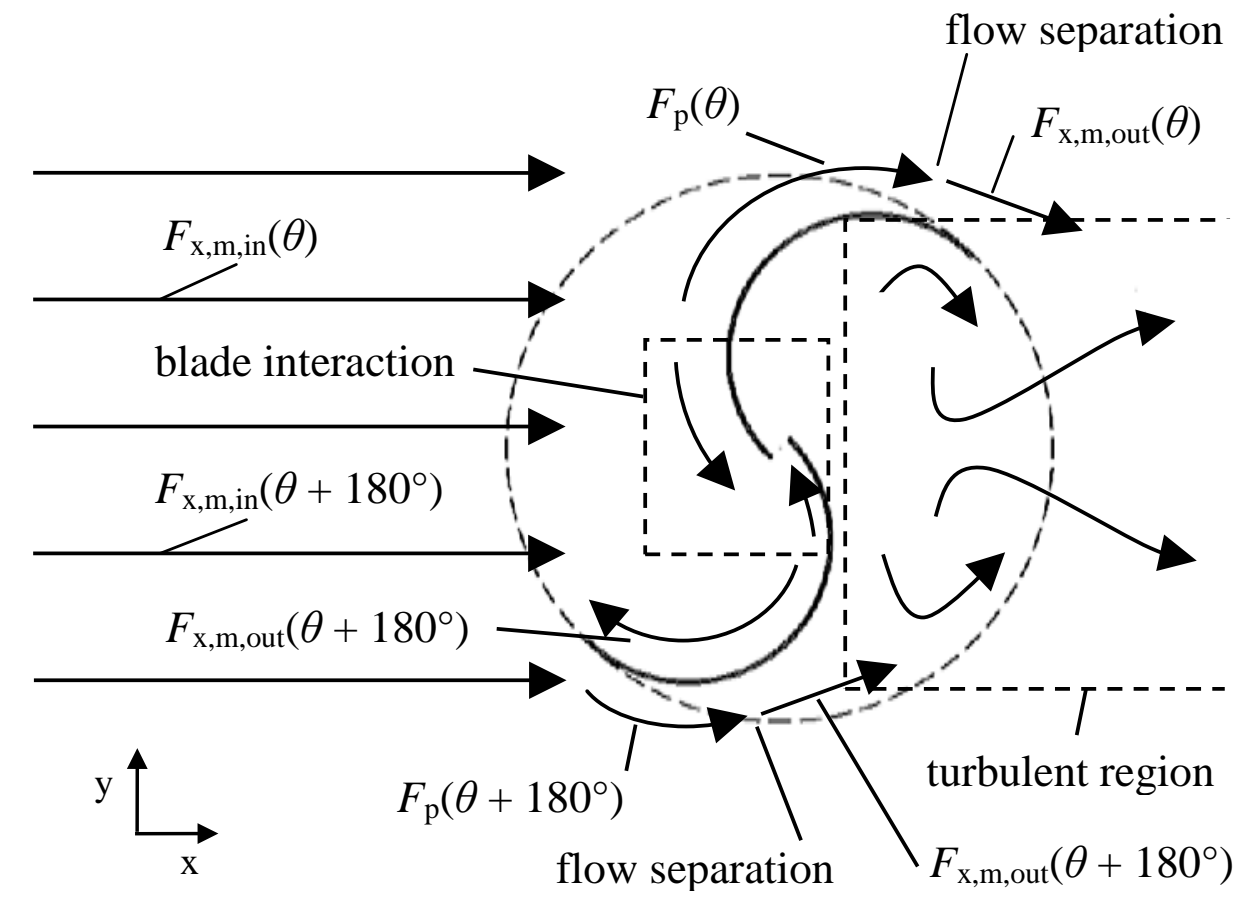

(a)

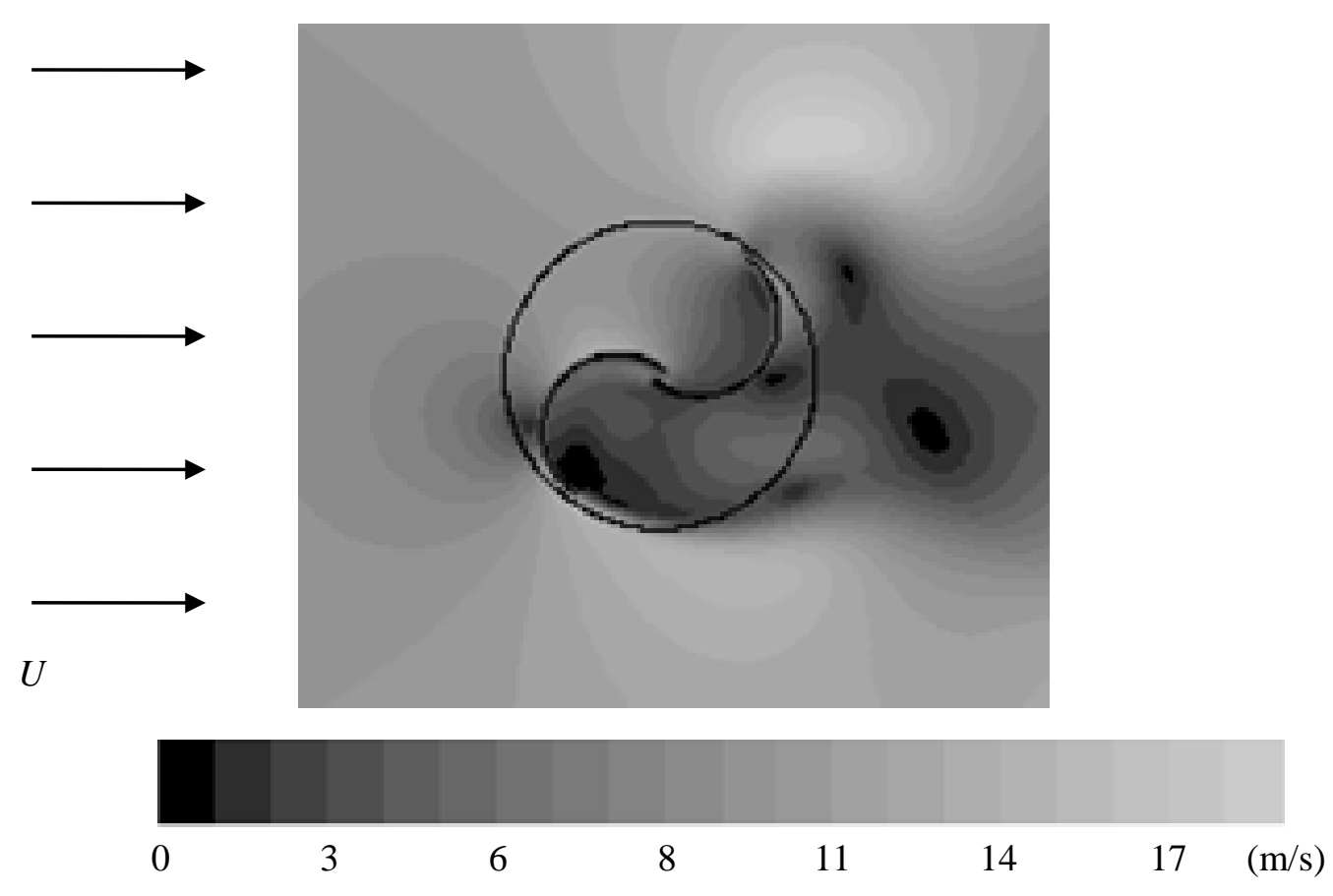

(b)

Figure 1: Two-blade configuration of a Savonius wind turbine (a) analytical flow field pattern and (b) numerical velocity contours 


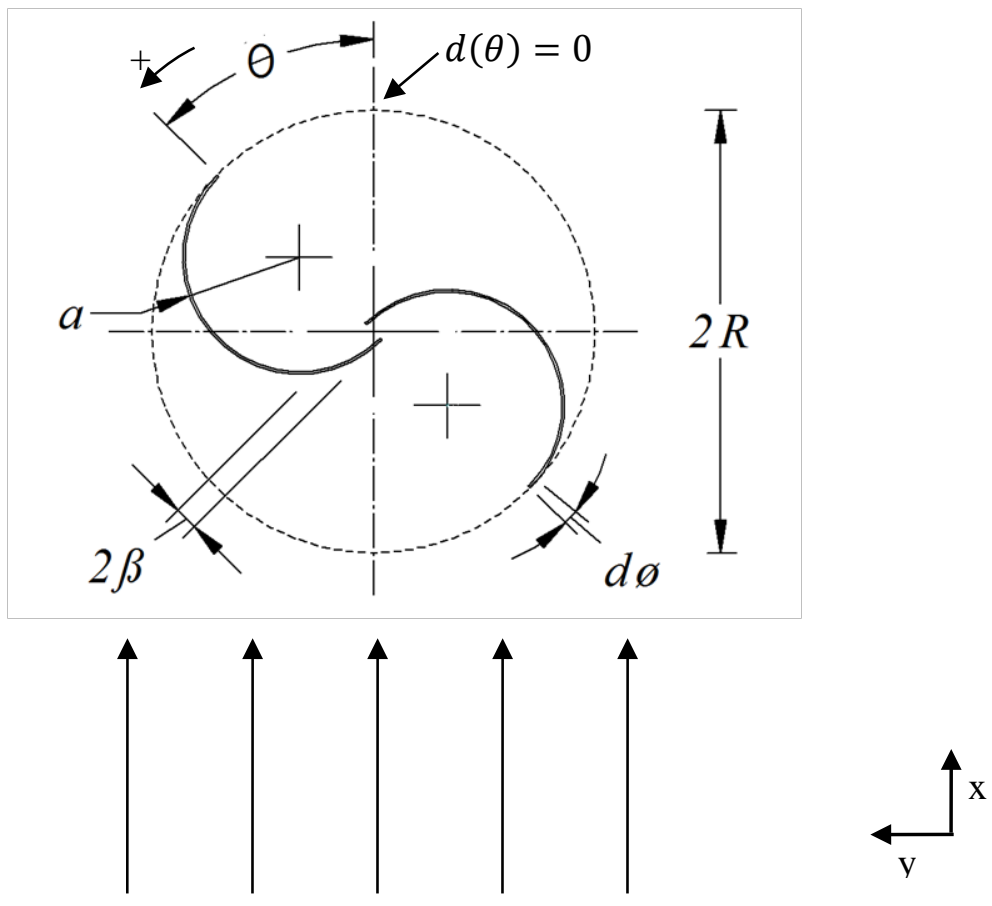

Figure 2: Geometrical variables of a Savonius VAWT

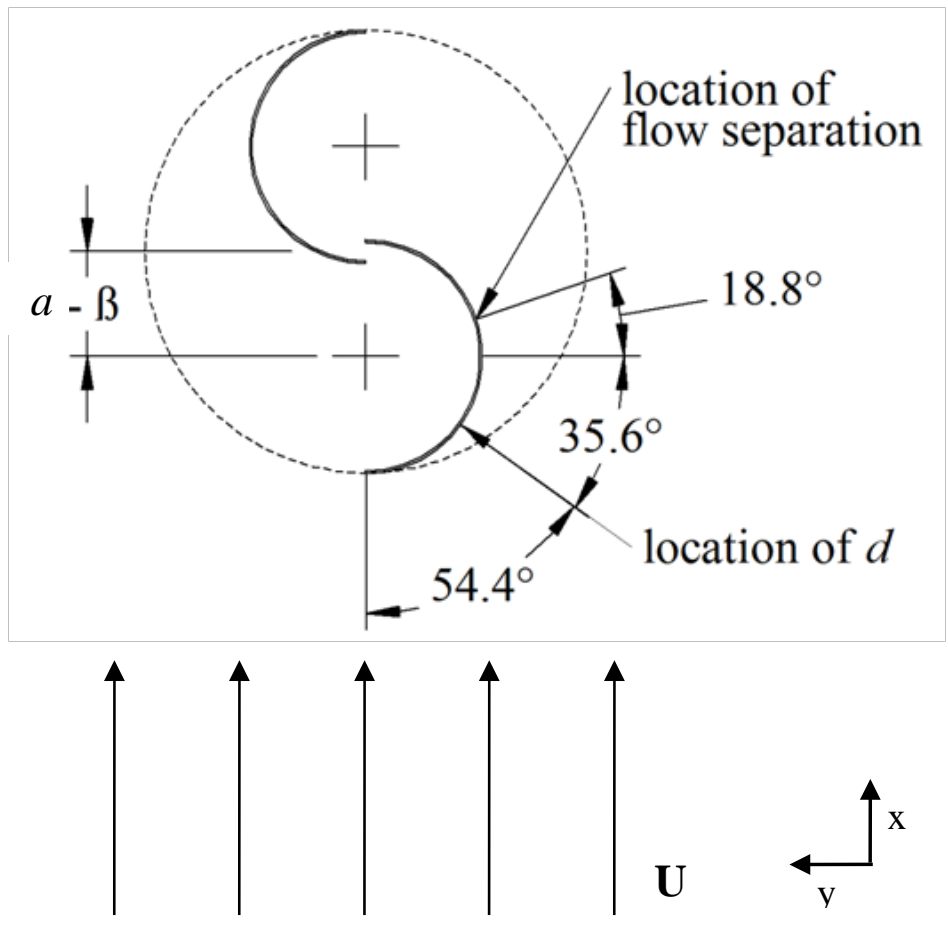

Figure 3: Location of $d$ on a Savonius wind turbine 


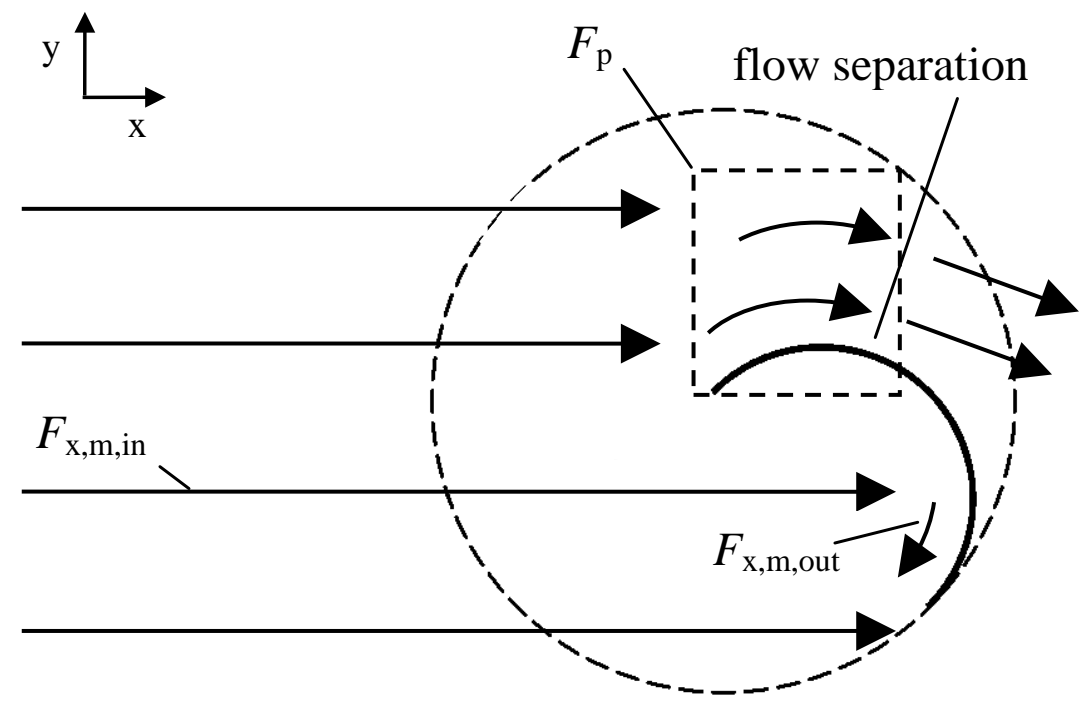

Figure 4: Flow field pattern for single blade configuration with rotor at $315^{\circ}$ rotation

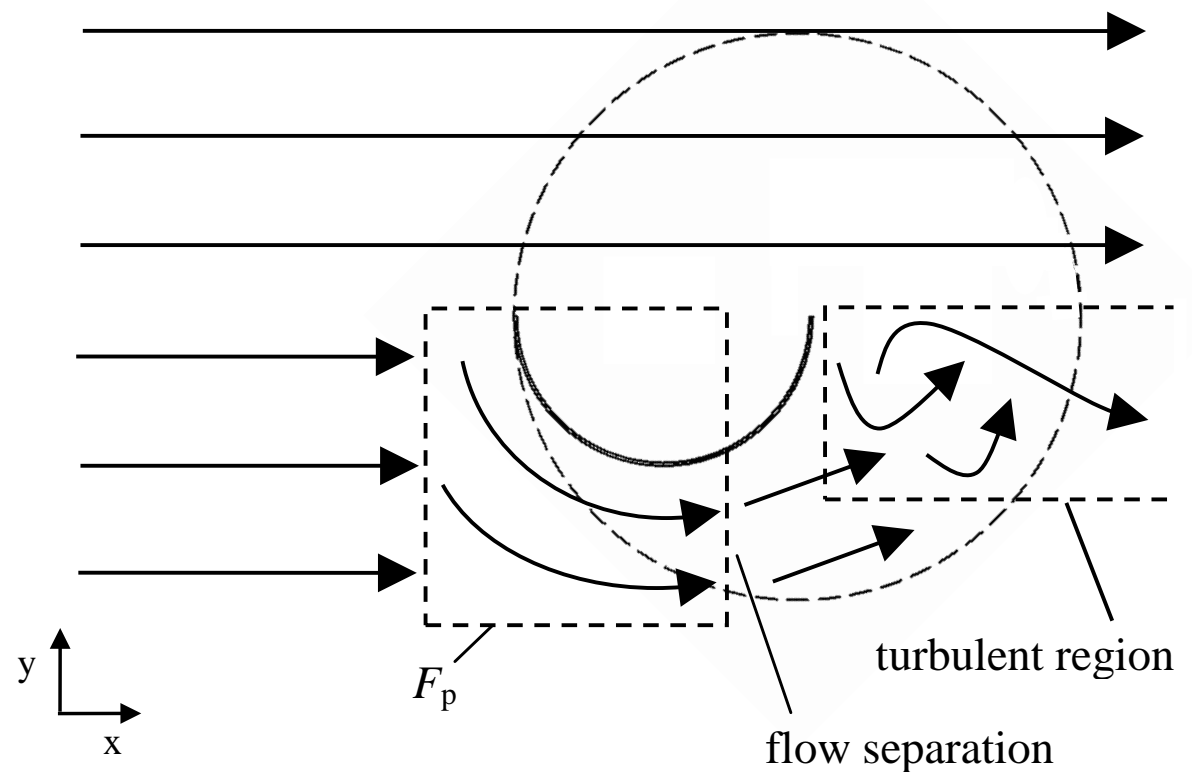

Figure 5: Flow field characteristics for single blade configuration with rotor at $180^{\circ}$ rotation 


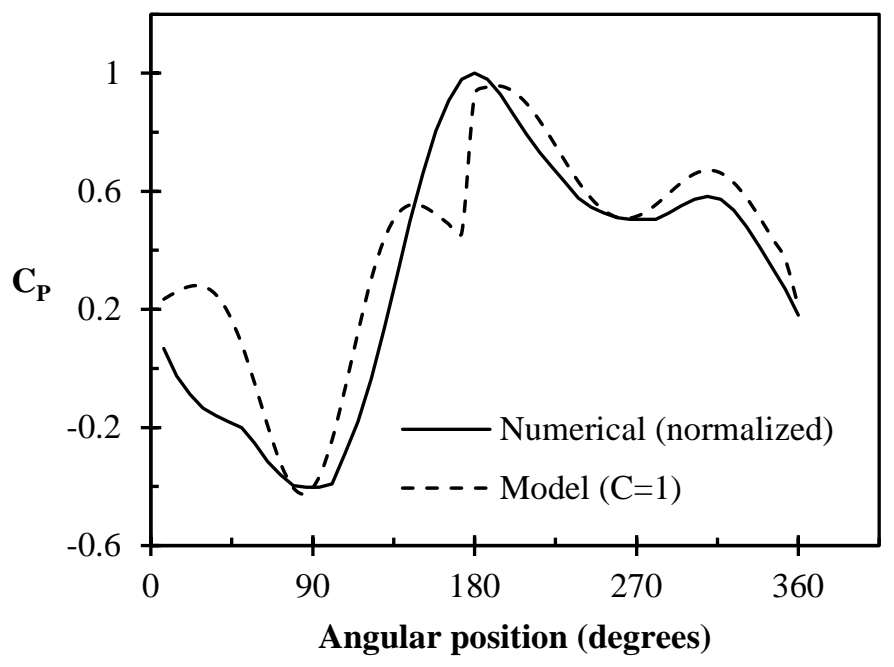

Figure 6: Transient power coefficient with $C=1$ for a single rotor Savonius VAWT

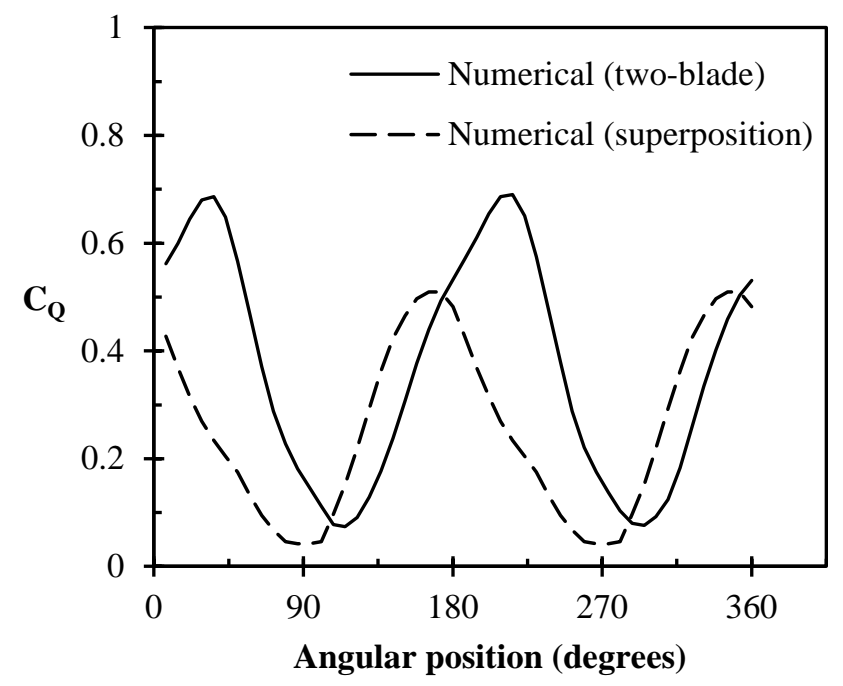

Figure 7: Predicted transient power coefficient for a two-blade Savonius VAWT 


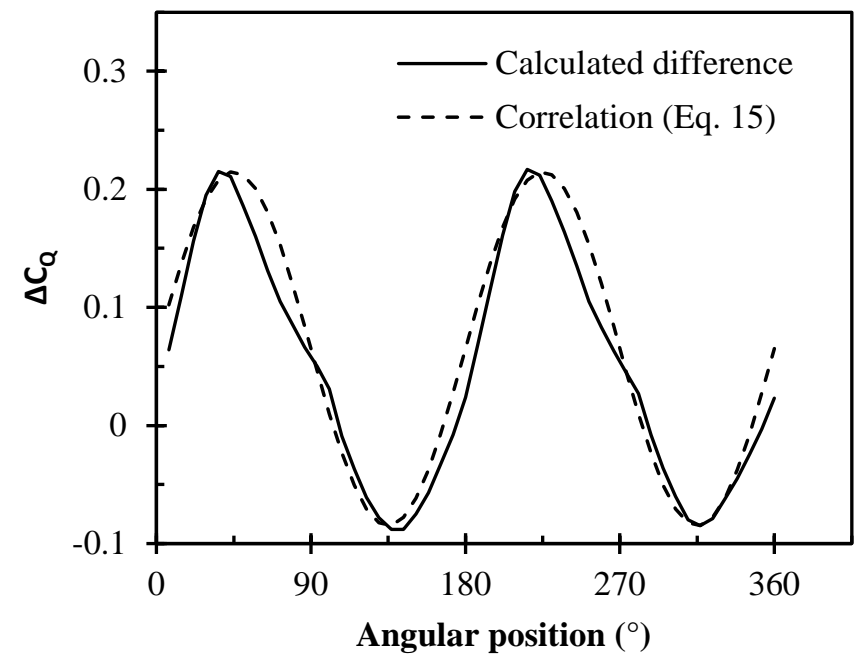

Figure 8: Varying rotor angles for a two-blade Savonius VAWT (representing $C$ for a two-blade design)

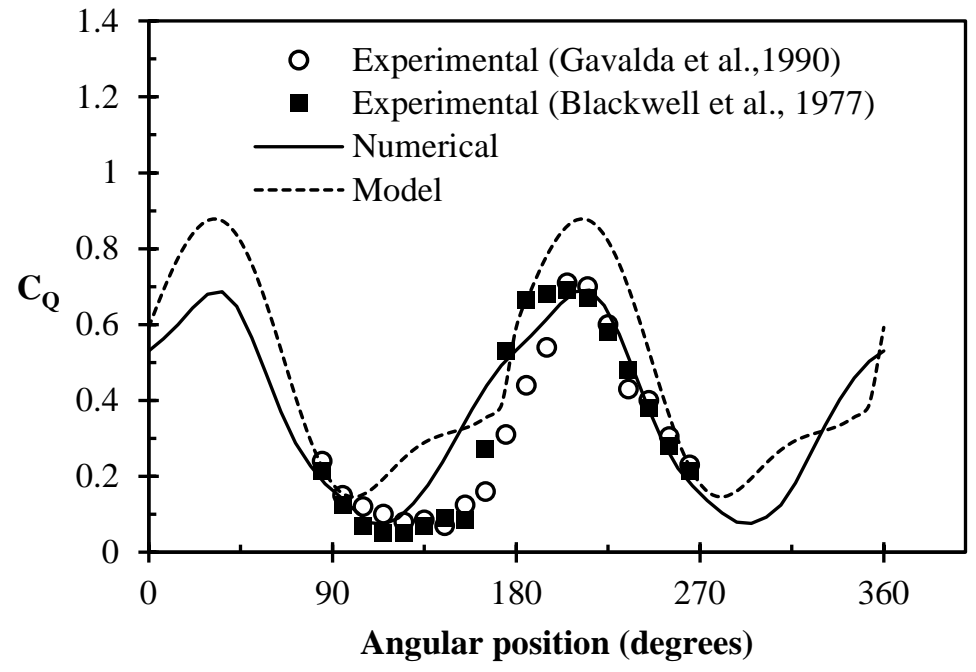

Figure 9: Predicted torque of a two-blade Savonius VAWT 


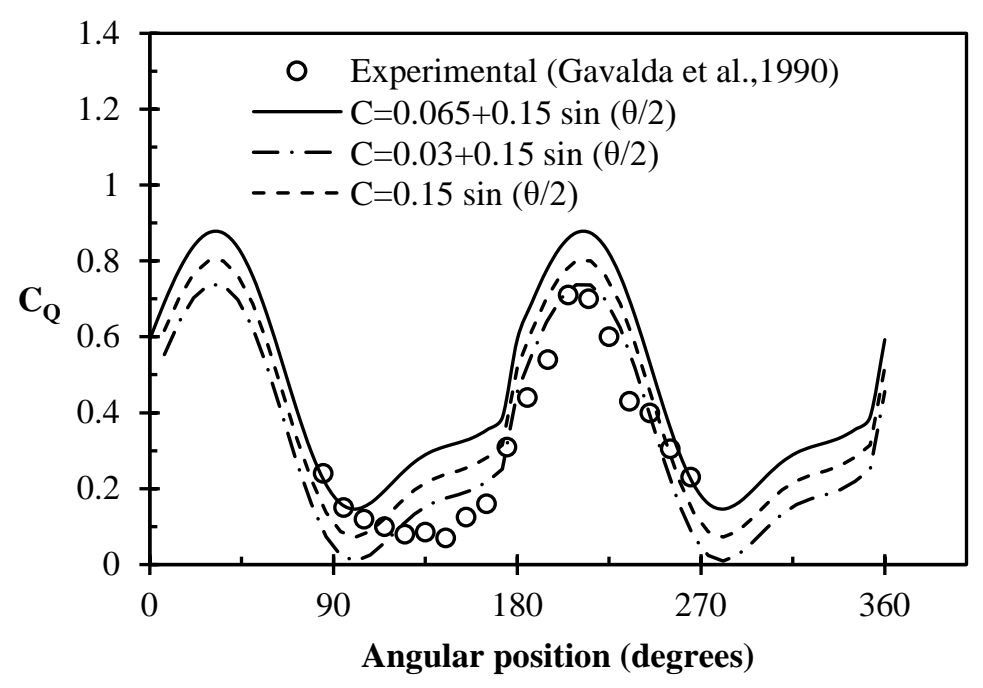

Figure 10: Predicted torque on a two-blade Savonius VAWT 